\title{
Content analysis of nutritional information in paediatric oral health education leaflets
}

Amit Arora ${ }^{1,2,3,4^{*}}$, Jenny Doan ${ }^{5}$, Jessamine Martinez ${ }^{5}$, Colin Phan ${ }^{5}$, Gregory S. Kolt ${ }^{1}$, Sameer Bhole ${ }^{3,5}$, Mark Fort Harris ${ }^{6}$, Jane Anne Scott ${ }^{7}$ and Debra Hector ${ }^{8}$

\begin{abstract}
Background: The aim of this study was to determine if paediatric oral health education leaflets with a food and nutritional focus provide messages that are clear and consistent with the current Australian Dietary Guidelines and the Infant Feeding Guidelines.

Methods: Forty-three leaflets aimed at parents were sourced from Australian state and territory Health Departments, oral health industry partners and commercial organisations, and a content analysis was performed. Recommendations on food and drink type, consumption frequency and general diet and nutrition advice were considered and cross-referenced with the Australian Dietary Guidelines and the Infant Feeding Guidelines to identify areas of consistency and discrepancy.

Results: Twenty leaflets recommended reducing the consumption of sugary and/or acidic food, while 23 leaflets recommended reducing the consumption of sugary and/or acidic drinks. The majority of the leaflets advised water $(n=35)$ and milk $(n=23)$ to drink. Although 33 leaflets encouraged a healthy diet, seven of these did not specify what a healthy diet was. Twenty-eight leaflets provided early childhood-related (0-2 years) feeding advice. Confusing messages were found in nine leaflets, with ambiguous recommendations that were open to individual interpretation.

Conclusions: There were some inconsistencies between the leaflets and the dietary and infant feeding guidelines in Australia; and across the leaflets, as not all important messages were included in any one leaflet. Government Health Departments and other relevant agencies should ensure that advisory messages regarding diet, particularly those with dental implications, are clear, complete and consistent across all dental educational leaflets.
\end{abstract}

Keywords: Content analysis, Children, Nutrition, Oral health, Leaflets, Health education

\section{Background}

Dental caries (decay) is a preventable oral disease affecting children, teenagers, and adults worldwide [1]. Despite the marked decline in dental caries in developed countries over the past 30 years, the prevalence of dental caries remains unacceptably high in children and is a major public health problem [2]. Bagramian et al. [3] reported that epidemiological data from different countries show that there is a marked increase in the prevalence of dental caries since the mid-1990s on a global scale. In 2007 , it was noted that $46 \%$ of Australian children aged

\footnotetext{
* Correspondence: a.arora@westernsydney.edu.au

'School of Science and Health, Western Sydney University, Campbelltown, NSW, Australia

${ }^{2}$ Discipline of Paediatrics and Child Health, Sydney Medical School,

Westmead, NSW, Australia

Full list of author information is available at the end of the article
}

6 years had an average of two 'decayed teeth', 'teeth missing due to caries', or 'filled primary (baby) teeth' [4]. Armfield and Spencer [5] have reported that since the mid-1990s, the caries experience in Australian children has increased in primary teeth and the burden appears to be carried over to permanent (adult) teeth.

Although dental caries has a multifactorial aetiology, dietary sugars play a significant role in caries initiation and development $[6,7]$. In recent years there has been a call for oral health promotion to utilise the common risk factor approach $[8,9]$ as diets high in sugar have been linked to both obesity and dental caries [7, 10]. Although both of these chronic conditions are preventable, their prevalence in young children has been on the rise since mid-1990s [11] raising concern over the consumption of foods high in sugar and fat [12]. 
Free sugars, which include added sugars and sugars naturally present in honey, syrups and fruit juices are cariogenic [7]. The WHO recommends that both adults and children should reduce the intake of free sugars to less than $10 \%$ of total energy intake [7], however the results of the 2011-2012 Australian Health Survey identified that $52.2 \%$ of children aged $2-3$ years old and $68.5 \%$ children aged 4-8 years exceeded this recommendation [13]. There is overwhelming evidence to suggest the cariogenic potential of different children's food and snack items $[2,14,15]$. In particular, items such as confectionery, cookies/biscuits, cake, sugar-sweetened beverages, and dried fruit are considered to be highly cariogenic $[2,14,15]$. On the other hand, fresh fruit is considered to be low in cariogenicity and items such as nuts, vegetables, and cheese and other dairy products are considered to be non-cariogenic $[2,14,15]$. In light of this evidence, the key dental-related dietary messages in the 2013 Australian Dietary Guidelines [16] and the 2012 Infant Feeding Guidelines [17] are:

1. Infants should be exclusively breastfed until around 6 months of age followed by the introduction of solid foods and breastfeeding should be continued until 12 months of age, and beyond if desired;

2. If the infant is not breast-fed, infant formulas should be used as an alternative to breast milk until 12 months of age and putting the infant to bed with a bottle of milk should be discouraged;

3. Limit the frequent consumption of added sugars in foods and drinks, in particular sticky foods;

4. Limit the consumption of acidic drinks, in particular fruit juices;

5. Encourage the consumption of fluoridated tap water;

6. From 6 months of age milk and water should be offered in a cup rather than a feeding bottle;

7. Pacifiers should not be dipped in honey, jam or any other sugary substance;

8. Discourage sharing of spoons to limit the spreading of bacteria.

9. Encourage the consumption of fresh fruits and vegetables.

While government preventive health policies aim to reduce levels of sugar and fat consumption [18], current approaches in dentistry rely heavily on one-to-one dietary advice given by oral health professionals to patients [19]. Studies have reported, however, that dentists either do not give dietary advice, or if they do, it is usually of variable quality [20] or given with minimal patient interaction [21, 22]. Health education leaflets are frequently used by oral health professionals as a means of communicating dietary advice. Although the usefulness of leaflets at improving oral health outcomes is unclear, they may be useful in bridging the communication gap between dentist and patient [22] if they are designed in a clear, concise, and consistent manner, and if they adhere to accepted and current guidelines. Furthermore, many oral health professionals feel that leaflets help to reinforce information discussed with patients [22]. It is essential, therefore, that any dietary advice given as part of oral health promotion is in accordance with evidencebased nutrition guidelines, thereby strengthening the common risk factor approach to health promotion and minimising conflicting and confusing messages to the public. The aim of this study was to determine if the paediatric oral health education leaflets with a food and nutritional focus available in Australia provide messages that are clear and consistent with current Australian Dietary Guidelines (ADG) [16] and the Infant Feeding Guidelines (IFG) [17].

\section{Methods}

\section{Paediatric oral health leaflets}

The Australian state and territory Health Departments, oral industry partners and commercial organisations were contacted for all available oral health education leaflets pertinent to children aged 0-17 years. Hardcopy and/or online availability were determined. In the case that leaflets were made known but not readily available, the study author (AA) directly contacted the relevant publishers. Sixty leaflets were sourced.

\section{Qualitative content analysis}

A manual qualitative analysis of the leaflets was conducted in several phases to obtain a detailed overview of the content.

\section{Phase 1}

All leaflets were initially screened for the presence or absence of any diet and/or nutrition-related information. Seventeen leaflets were excluded in this phase as not having any nutritional and/or dietary advice. The remaining 43 leaflets (Table 1) were from the government $(n=32)$, professionally-accredited associations $(\mathrm{n}=3)$, independent education institutions $(\mathrm{n}=3)$ and the oral health industry $(n=5)$. The title of the leaflet, source, publisher and year of publication were noted in this phase.

\section{Phase 2}

The 43 leaflets were then screened for any dietary and/ or nutrition education messages or images that were confusing and/or were open to misinterpretation. If the message or the graphic was not clear, the reasons were noted. 
Table 1 Details of Australian paediatric oral health leaflets including dietary advice and/or nutritional information to prevent caries

\begin{tabular}{|c|c|c|c|c|c|}
\hline No. & Title & Publisher $^{\mathrm{b}}$ & Source $^{b}$ & Date & Infant diet advice \\
\hline 1 & 7 tips for healthy baby teeth & Australian Dental Association & $P$ & Unknown & Y \\
\hline 2 & Dental care for babies and young children & Australian Dental Association & $P$ & 2007 & Y \\
\hline 3 & Oral Health for infants and toddlers & Colgate & $\mathrm{O}$ & 2007 & Y \\
\hline 4 & Teething, Preventing tooth decay & Colgate & $\mathrm{O}$ & Unknown & Y \\
\hline 5 & Oral Health for children 3-12 & Colgate & $\mathrm{O}$ & 2005 & - \\
\hline 6 & Teaching your child good brushing habits & Macleans & $\mathrm{O}$ & 2009 & Y \\
\hline 7 & Teething & Dental Health Services Victoria & G & 2010 & Y \\
\hline 8 & Tooth tips Thumb and finger sucking & Dental Health Services Victoria & G & 2010 & Y \\
\hline 9 & Eat well Fact Sheet for Parents & Dental Health Services Victoria & G & 2009 & - \\
\hline 10 & Drink well Fact Sheet for Parents & Dental Health Services Victoria & G & 2009 & - \\
\hline 11 & Solid Kids have Healthy Teeth (Infants) & Derbarl Yerrigan Health Service & । & Unknown & Y \\
\hline 12 & Solid Kids have Healthy Teeth (Toddlers) & Derbarl Yerrigan Health Service & । & Unknown & Y \\
\hline 13 & Give your Child's Teeth a Healthy Start & SA Health & G & Unknown & Y \\
\hline 14 & Dental Information for Parents/Carers & NSW Health & G & 2009 & Y \\
\hline 15 & Teach your baby to drink from a cup & NSW Health & G & 2009 & Y \\
\hline 16 & NSW Messages for a Healthy Mouth & NSW Health & G & 2007 & Y \\
\hline 17 & Caring for babies' teeth & NSW Health & G & 2001 & Y \\
\hline 18 & Keep your child's teeth healthy & NSW Health & G & 2007 & Y \\
\hline 19 & Tooth Smart & NSW Health & G & 2011 & Y \\
\hline 20 & Good Oral Health for Children & NSW Health & G & 2004 & - \\
\hline 21 & Keep smiling while you are pregnant & NSW Health & G & 2009 & Y \\
\hline 22 & Healthy Mouths for Aboriginal People & NSW Health & G & 2010 & - \\
\hline 23 & Healthy Smiles for Kids under 5 (Aboriginal) & NSW Health & G & 2013 & Y \\
\hline 24 & Keep our Kids Smiles Strong & NSW Health & G & 2011 & Y \\
\hline 25 & Sugar in Breakfast Foods & NSW Health & G & 2011 & - \\
\hline 26 & Sugar in Snack Foods & NSW Health & G & 2011 & - \\
\hline 27 & Tooth Smart - Grazing on Foods and Drinks & NSW Health & G & 2014 & - \\
\hline 28 & Tooth Smart - Tips to eat less Sweets & NSW Health & G & 2014 & - \\
\hline 29 & Tooth Smart - Tips to stop sweet drinks & NSW Health & G & 2014 & - \\
\hline 30 & Tooth Smart - Goals and Rewards & NSW Health & G & 2014 & - \\
\hline 31 & Tooth Smart - Reading Food and Drink Labels & NSW Health & G & 2014 & - \\
\hline 32 & Tooth Smart - Stopping the Bottle (Baby) & NSW Health & G & 2014 & Y \\
\hline 33 & Tooth Smart - Stopping the Bottle & NSW Health & G & 2014 & Y \\
\hline 34 & Tooth Smart - Meals for children & NSW Health & G & 2014 & - \\
\hline 35 & Top Dental Tips for young people & NSW Health & G & 2014 & - \\
\hline 36 & Don't rot your baby's teeth & Queensland Health & G & Unknown & Y \\
\hline 37 & Looking after young mouths & Queensland Health & G & Not Specified & Y \\
\hline 38 & Caring for your child's smile & SA Dental Service & G & Unknown & Y \\
\hline 39 & Caring for your Child's smile ( $0-6$ years) & WA Dental Health Services & G & Unknown & Y \\
\hline 40 & Thumbsucking and Dummies & WA Dental Health Services & G & 2009 & Y \\
\hline 41 & Healthy eating equals healthy teeth & Australian Dental Association & $P$ & Unknown & Y \\
\hline 42 & Dental Care for Kids & Pacific Smiles Dental & $\mathrm{O}$ & 2011 & - \\
\hline 43 & Decay - Whose teeth are at risk? & University of South Australia & I & Unknown & Y \\
\hline
\end{tabular}




\section{Phase 3}

The leaflets were screened for any infant (0-2 years) feeding advice and the responses were dichotomised. A score of 0 was given if no infant feeding advice was given. A score of 1 indicated the presence of infant feeding advice. In particular, the leaflets were screened for consistencies on the following messages:

a. Any message on breastfeeding, in particular nighttime breastfeeding and demand breastfeeding;

b. Any advice on bottle feeding including advice on weaning and replacing sugary drinks with water; and

c. Any education messages on pacifier use including advice on not dipping the dummy in sugary liquids and sharing dummies.

\section{Phase 4}

The leaflets were then screened for dietary and/or nutritional advice for preschool aged children (3-5 years), and school aged children (6 years to 17 years). A score of 0 was given if no dietary and/or nutritional advice was given. A score of 1 indicated the presence of dietary and/or nutritional advice. In particular, the leaflets were screened for consistencies on the following content:

a. Advice to decrease the frequency and/or amount of consumption of sugary and/or acidic foods.

b. Advice to restrict sugary and/or acidic foods to meal times.

c. Advice on avoiding or reducing the consumption of sticky food.

d. Examples of "bad" foods and/or drinks that may contain high levels of sugars, saturated fats, or salt as per the ADG and IFG guidelines.

e. Advice to decrease the frequency and/or amount of consumption of sugary and/or acidic drinks.

f. Advice to restrict sugary and/or acidic drinks to meal times.

g. Advice on consumption of water, in particular fluoridated water.

h. Advice on consumption of milk and/or other dairy products.

i. Advice on consumption of fruits and vegetables.

\section{Analysis}

STATA version 13 statistical software (Statcorp) was used for the analysis. Cronbach's alpha was used to assess the internal consistency of leaflets targeting children aged 0-2 years, $3-5$ years and 6-17 years. As a rule of thumb, an alpha $>0.9$ is considered excellent, $>0.8$ good, $>0.7$ acceptable, $>0.6$ questionable, $>0.5$ poor and $<0.5$ unacceptable [23].

\section{Results}

Reliability

The internal consistency of messages was poor for leaflets targeted towards parents of infants (0-2 years) (alpha $=0.46)$. In comparison, alpha coefficients demonstrated that the internal consistency of the messages was acceptable for leaflets targeted towards parents of preschool aged children $(2-5$ years $) \quad($ alpha $=0.73)$, and school aged children $(6-17$ years) (alpha $=0.75)$.

\section{Content analysis}

Table 2 indicates the key dietary advice of the 43 leaflets. Twenty leaflets recommended reducing the consumption of sugary and/or acidic foods, while 23 leaflets recommended reducing the consumption of sugary and/ or acidic drinks. When discussing food, sugar $(n=20)$ was mentioned in more leaflets than acidity $(n=4)$. Sugar $(n=23)$ was also mentioned more often than acidity $(\mathrm{n}=8)$ with regard to messages around drinks. A total of 13 leaflets suggested restricting sugary and/or acidic food and/or drink consumption to meal times with ten leaflets referring specifically to food, while ten referred specifically to drinks.

The majority of leaflets $(n=35)$ recommended water to drink while 23 leaflets recommended milk. Nineteen leaflets specifically advised drinking fluoridated or tap water. Eight leaflets made a distinction that flavoured milk was not beneficial. Just over half of the leaflets $(n=24)$ identified fruit juice as a potential contributor to tooth decay.

Over half of the leaflets specified examples of unhealthy drinks $(n=25)$, while only 19 leaflets gave specific examples of unhealthy foods. Five leaflets recommended completely removing sweets from the diet and only eight leaflets advised avoidance of "sticky" foods.

\section{Incomplete messages}

Four leaflets provided general information about oral health and nutrition, but did not provide any specific recommendations or guidance. For example, leaflets 1 and 3 described foods and/or drinks that could potentially increase the risk of early childhood caries, but did not suggest any alternatives that could be placed in the baby bottle or clearly state the way foods/and or drinks should be consumed.

\section{Confusing messages}

Nine leaflets contained potentially confusing messages. Some examples are listed in Table 3.

\section{Snack recommendations}

Thirty-three leaflets advised to eat a "healthy diet". Seven of these leaflets however ambiguously referred to "healthy foods" or a "nutritious diet" without further examples. Of 
Table 2 Dietary messages contained in leaflets ${ }^{a}$

\begin{tabular}{|c|c|c|c|c|c|c|c|c|c|c|c|c|}
\hline \multirow[t]{2}{*}{ No. } & \multicolumn{4}{|c|}{ Sugary and/or Acidic Foods } & \multicolumn{7}{|c|}{ Sugary and/or Acidic Drinks } & \multirow{2}{*}{$\begin{array}{l}\text { Confusing } \\
\text { Message }\end{array}$} \\
\hline & Reduce & Meal Times & "Bad Foods" & Sticky Foods & Reduce & Meal Times & Water (any) & Water (fluoridated) & Milk & Flavoured Milk & Fruit Juice & \\
\hline 1 & - & - & - & - & - & - & Y & $\mathrm{Y}$ & - & Y & Y & - \\
\hline 2 & Y & - & Y & - & Y & Y & Y & Y & - & Y & Y & - \\
\hline 3 & - & - & Y & - & Y & - & Y & - & - & Y & Y & - \\
\hline 4 & - & - & - & - & Y & - & Y & Y & - & - & Y & - \\
\hline 5 & Y & - & - & - & Y & - & Y & Y & - & - & Y & - \\
\hline 6 & - & - & Y & - & - & - & Y & - & - & - & Y & Y \\
\hline 7 & - & - & Y & - & - & - & Y & - & Y & - & - & - \\
\hline 8 & - & Y & Y & Y & - & - & Y & Y & Y & - & Y & - \\
\hline 9 & Y & $Y$ & Y & Y & Y & $Y$ & $Y$ & - & Y & - & Y & - \\
\hline 10 & - & - & - & - & Y & - & Y & $Y$ & Y & - & Y & Y \\
\hline 11 & - & - & $Y$ & - & - & - & Y & - & Y & - & - & Y \\
\hline 12 & Y & Y & Y & - & - & Y & Y & - & Y & - & - & - \\
\hline 13 & - & - & - & - & - & - & Y & Y & Y & Y & Y & - \\
\hline 14 & - & - & Y & Y & - & - & $Y$ & Y & Y & - & Y & $Y$ \\
\hline 15 & - & - & - & - & Y & - & $Y$ & - & Y & - & Y & - \\
\hline 16 & Y & - & $Y$ & Y & $Y$ & - & $Y$ & $Y$ & Y & - & Y & - \\
\hline 17 & - & Y & - & - & Y & Y & $Y$ & - & - & - & Y & - \\
\hline 18 & - & - & - & - & - & - & $Y$ & $Y$ & $Y$ & - & - & - \\
\hline 19 & - & Y & Y & Y & - & Y & Y & Y & Y & Y & - & Y \\
\hline 20 & Y & - & Y & - & Y & - & Y & Y & Y & Y & Y & - \\
\hline 21 & Y & $Y$ & Y & - & Y & - & $Y$ & - & Y & - & Y & Y \\
\hline 22 & Y & - & Y & - & Y & - & Y & Y & - & - & - & - \\
\hline 23 & Y & - & Y & Y & Y & - & $Y$ & Y & Y & - & $Y$ & - \\
\hline 24 & - & - & - & - & - & - & Y & - & Y & - & - & - \\
\hline 25 & - & $Y$ & Y & - & - & - & - & - & - & - & - & - \\
\hline 26 & - & - & Y & - & - & - & Y & - & - & - & - & - \\
\hline 27 & Y & - & - & - & Y & - & - & - & - & - & - & - \\
\hline 28 & Y & - & Y & - & - & - & - & - & - & - & - & - \\
\hline 29 & - & - & - & - & Y & Y & Y & - & - & Y & Y & - \\
\hline 30 & Y & - & - & - & - & - & - & - & $Y$ & - & - & - \\
\hline 31 & Y & - & - & - & Y & - & - & - & - & - & - & - \\
\hline 32 & - & - & - & - & - & - & $Y$ & - & Y & - & - & - \\
\hline 33 & - & - & - & - & - & - & Y & - & Y & - & - & - \\
\hline 34 & Y & - & $Y$ & - & Y & - & - & - & Y & Y & - & - \\
\hline 35 & Y & - & - & Y & Y & $Y$ & Y & Y & Y & - & - & - \\
\hline 36 & - & Y & - & - & Y & Y & - & - & - & - & - & - \\
\hline 37 & Y & Y & $Y$ & - & Y & Y & Y & - & Y & - & Y & Y \\
\hline 38 & Y & - & - & - & Y & - & Y & $Y$ & - & - & Y & - \\
\hline 39 & Y & - & - & $Y$ & - & - & $Y$ & - & - & - & Y & $Y$ \\
\hline
\end{tabular}


Table 2 Dietary messages contained in leaflets ${ }^{\mathrm{a}}$ (Continued)

\begin{tabular}{lllllllllll}
\hline 40 & - & - & - & - & - & - & - & - & - & - \\
41 & $Y$ & - & $Y$ & - & $Y$ & - & $Y$ & $Y$ & $Y$ & - \\
42 & $Y$ & - & - & - & $Y$ & - & $Y$ & $Y$ & - & - \\
43 & - & $Y$ & - & - & - & $Y$ & $Y$ & $Y$ & - & - \\
\hline a "Y" refers to a & & &
\end{tabular}

a "Y" refers to a Yes

those leaflets that provided healthy snack recommendations $(n=25)$, all indicated fruit and vegetables, while the majority also suggested cheese and dairy products (Table 4).

\section{Feeding and pacifier advice for $\mathbf{0}-\mathbf{2}$ years}

Table 5 details the content of 28 leaflets in the sample that provided advice in relation to feeding and pacifier use for 0-2 year olds (infants). Although 25 of the 28 leaflets advised limiting bottle feeding in general, only 17 advised against night-time bottle feeding. Eleven leaflets recommended placement of water in the bottle for prolonged feeding, and seven gave specific examples of fluids that should not be placed in the bottle. Although ten leaflets encouraged breastfeeding, none specifically promoted the optimal duration of exclusive and continued breastfeeding of 6 and 12 months or more, respectively. Nearly half of these leaflets $(n=14)$ suggested introducing a cup at age 6 months and only four leaflets suggested to start solid foods at age six months. Ten leaflets gave advice on the use of a pacifier, all of which advised not to dip the pacifier in sugary products such as honey or jam.

\section{Use of images}

Six leaflets used relevant images to accompany the message being delivered, however some of these did not have any or appropriate words accompanying the image (Table 3).

\section{Discussion}

The findings of this study indicate that the dietary advice and nutritional information in leaflets aimed at preventing tooth decay in children in Australia does not always align with the national dietary and infant feeding guidelines. In addition, many of the important items of information were inconsistently included across leaflets, with each individual leaflet lacking at least one key item of information and few leaflets containing the majority of or all key items. Further, some dietary messages to prevent dental decay were unclear and hence could be subject to misinterpretation by individuals.

The majority of the leaflets did not contain any recommendations specific to the amount and timing of sugary and/or acidic food consumption, i.e. key information specific to dietary prevention of caries. The ADGs [16] emphasise established evidence with respect to the amount, timing and frequency of consumption of these food types as important in the prevention of tooth decay. [24]. It is generally recommended to restrict sugar to meal times, so the tooth enamel is given an opportunity to remineralise and return to a neutral $\mathrm{pH}$ [25]. In contrast, frequent snacking on sugary foods and drinks between main meals allows for continuous acid attack

Table 3 Examples of unclear and confusing information in leaflets

\begin{tabular}{|c|c|c|}
\hline No. & Leaflet content & Potential for confusion/misinterpretation \\
\hline 6 & $\begin{array}{l}\text { "Foods that are high in sugar (such as lollies and soft drinks) or food } \\
\text { acids (such as some fruit juices) can be bad for teeth as they can lead to } \\
\text { cavities or loss of tooth enamel." }\end{array}$ & $\begin{array}{l}\text { States 'some' fruit juices can be bad. Does not expand further on } \\
\text { which types can be good or which can be bad. }\end{array}$ \\
\hline 12 & $\begin{array}{l}\text { Images to demonstrate food and drinks to "avoid" without any written } \\
\text { message }\end{array}$ & $\begin{array}{l}\text { Use of images without clear labelling to identify what they are } \\
\text { supposed to represent could lead to misinterpretation. }\end{array}$ \\
\hline 19 & $\begin{array}{l}\text { "Fruit Drinks (with added sugar)" } \\
\text { (Under title: "Stop") }\end{array}$ & $\begin{array}{l}\text { Fruit Drinks is an ambiguous term, as it could refer to juice, cordial, or } \\
\text { a fruit-flavoured beverage. Also suggests drinks such as fruit juice with } \\
\text { no added sugar are okay. }\end{array}$ \\
\hline 39 & $\begin{array}{l}\text { "This will help prevent 'Early Childhood Caries' which is decay caused by } \\
\text { frequent, prolonged use of a bottle containing sweet liquids such as } \\
\text { milk, juice or cordial." AND } \\
\text { "Water (and milk in moderation) is the best thirst quencher." }\end{array}$ & $\begin{array}{l}\text { Contradicts by linking milk to causing Early Childhood Caries, then } \\
\text { later states that milk in moderation is the best thirst quencher. }\end{array}$ \\
\hline 41 & $\begin{array}{l}\text { "Offer a diet high in fresh fruits and vegetables, wholegrain cereals, lean } \\
\text { meats and dairy products." AND } \\
\text { "Many healthy foods (such as fruit) contain high amounts of sugar." }\end{array}$ & $\begin{array}{l}\text { Contradicts by recommending fruit in diet, then later states that it is } \\
\text { high in sugar. }\end{array}$ \\
\hline
\end{tabular}


Table 4 Leaflet content in relation to snack recommendations ${ }^{a}$

\begin{tabular}{|c|c|c|c|}
\hline No. & Fruits \& Vegetables & Cheese & Dairy \\
\hline 1 & - & - & - \\
\hline 2 & Y & - & Y \\
\hline 3 & Y & - & - \\
\hline 4 & - & - & - \\
\hline 5 & Y & - & Y \\
\hline 6 & Y & Y & Y \\
\hline 7 & Y & - & Y \\
\hline 8 & Y & Y & Y \\
\hline 9 & Y & Y & Y \\
\hline 10 & Y & - & - \\
\hline 11 & - & - & - \\
\hline 12 & Y & Y & - \\
\hline 13 & - & - & - \\
\hline 14 & Y & Y & - \\
\hline 15 & Y & Y & Y \\
\hline 16 & Y & Y & - \\
\hline 17 & - & - & - \\
\hline 18 & - & - & - \\
\hline 19 & Y & Y & Y \\
\hline 20 & Y & - & Y \\
\hline 21 & Y & - & Y \\
\hline 22 & Y & Y & Y \\
\hline 23 & Y & Y & Y \\
\hline 24 & - & - & - \\
\hline 25 & - & - & - \\
\hline 26 & $Y$ & $Y$ & - \\
\hline 27 & $Y$ & $Y$ & $Y$ \\
\hline 28 & $Y$ & - & - \\
\hline 29 & - & - & - \\
\hline 30 & $Y$ & - & $Y$ \\
\hline 31 & - & - & - \\
\hline 32 & - & - & - \\
\hline 33 & - & - & - \\
\hline 34 & $Y$ & $Y$ & $Y$ \\
\hline 35 & $Y$ & $Y$ & $Y$ \\
\hline 36 & - & - & - \\
\hline 37 & $Y$ & $Y$ & $Y$ \\
\hline 38 & - & - & - \\
\hline 39 & - & - & - \\
\hline 40 & - & - & - \\
\hline 41 & Y & $Y$ & Y \\
\hline 42 & - & - & - \\
\hline 43 & - & - & - \\
\hline
\end{tabular}

a " $\mathrm{Y}$ " refers to a Yes (contained in leaflet) '-'refers to a ' $\mathrm{No}^{\prime}$ (not contained in leaflet) on tooth surfaces [25]. Banning sugary foods and drinks is a practice parents could be advised to adopt however more realistically parents should be advised to reduce the frequency of consumption of sugary foods by their children and restrict the consumption of sugary foods by their children to meal times only.

'Acidity' was mentioned less frequently than 'sugar' in the education leaflets. Although sugar consumption has a well-known association with tooth decay [6, 7], acidity also has relevant dental implications in the form of tooth erosion leading to possible complications such as severe tooth surface loss, tooth sensitivity, poor aesthetics, and dental abscess [26]. With increased marketing of sugarfree soft drinks and isotonic sports drinks, parents may be misled to believe that these make for better options for their children compared to their sugary counterparts. While this may be true with regards to a decreased risk for dental caries and obesity, these sugar-free beverages have negative dental consequences such as tooth erosion. It is important that more awareness is raised regarding the acidic content of sugar-free drinks and isotonic sports drinks so that parents can make more informed decisions.

In accordance with the ADG [16] and IFG [17], water consumption was advocated in the majority of leaflets. Tap/public water, which contains fluoride in most areas of Australia, was advised in more than half of the leaflets. The distinction between fluoridated tap water and non-public water such as bottled water, however, was not explicitly stated in all leaflets. Consumption of fluoridated tap water should be more strongly advocated as there is scientific evidence that the consumption of nonpublic water is positively associated with dental decay $[27,28]$. Further, while the majority of Australian states and territories are fluoridated [29], water in some rural areas remains non-fluoridated and this is a concern and therefore benefits of water instead of other drinks should be advocated to these populations [30].

Daily consumption of fruits and vegetables as recommended in the ADG [16], was consistently recommended by all leaflets that suggested healthy food examples. Aside from their commonly-known nutritional benefits, oral health benefits have been found in certain fruits. It has been reported that consumption of fibrous fruit after meals is potentially preventive against tooth decay due to the cleansing action and increased salivary flow [13]. Conversely, Arora et al. [31] demonstrated that frequent exposure to fruits was positively associated with dental decay, although causal evidence to support this association is lacking.

The ADG [16] mention avoiding "sticky" food, with a particular reference to dried fruit. Only one in five of the leaflets identified sticky foods as a problem with implications for dental caries. The longitudinal Vipeholm study 
Table 5 Content analysis of infant feeding and pacifier advice in leaflets aimed at early childhood (aged 0-2 years) ${ }^{a, c}$

\begin{tabular}{|c|c|c|c|c|c|c|c|}
\hline No. & Bottle Feeding & Water in bottle & No sugary fluids in bottle ${ }^{b}$ & Overnight feeding & Breast milk & Pacifier advice & Dipping pacifier in sugar \\
\hline 1 & Y & - & Y & Y & - & - & - \\
\hline 2 & Y & Y & - & - & - & Y & Y \\
\hline 3 & Y & Y & Y & - & - & Y & Y \\
\hline 4 & Y & Y & - & - & - & Y & Y \\
\hline 6 & Y & Y & - & - & - & - & - \\
\hline 7 & Y & - & - & Y & Y & Y & Y \\
\hline 8 & Y & - & - & - & - & - & - \\
\hline 11 & Y & Y & - & Y & Y & Y & Y \\
\hline 12 & Y & Y & - & Y & - & Y & Y \\
\hline 13 & Y & - & - & $Y$ & $Y$ & $Y$ & Y \\
\hline 14 & $Y$ & - & $Y$ & $Y$ & $Y$ & - & - \\
\hline 15 & Y & - & Y & $Y$ & $Y$ & - & - \\
\hline 16 & Y & Y & - & - & $Y$ & - & - \\
\hline 17 & Y & $Y$ & Y & $Y$ & - & - & - \\
\hline 18 & $Y$ & - & - & $Y$ & Y & - & - \\
\hline 19 & Y & - & - & - & - & - & - \\
\hline 21 & Y & - & - & $Y$ & $Y$ & - & - \\
\hline 23 & Y & - & Y & $Y$ & - & - & - \\
\hline 24 & Y & - & - & $Y$ & - & - & - \\
\hline 32 & $Y$ & Y & - & $Y$ & - & - & - \\
\hline 33 & Y & - & - & - & - & - & - \\
\hline 36 & Y & - & - & $Y$ & $Y$ & - & - \\
\hline 37 & Y & - & - & $Y$ & $Y$ & Y & Y \\
\hline 38 & - & - & - & - & - & - & - \\
\hline 39 & Y & Y & - & $Y$ & - & Y & Y \\
\hline 40 & - & - & - & - & - & $Y$ & Y \\
\hline 41 & - & - & - & - & - & - & - \\
\hline 43 & Y & Y & Y & $Y$ & - & - & - \\
\hline
\end{tabular}

a From a total of 24 infant-targeted leaflets

${ }^{\text {b }}$ Sugary fluids include milk, juice \& cordial

c " $Y$ " refers to a Yes

[24] reported that sticky foods consumed between meals increased the risk of decay due to their sticky texture, allowing for greater adherence to the tooth surface leading to longer exposure time to the tooth enamel. This ultimately means that there is slower clearance of the sticky foods, resulting in a continual acid attack without chance of tooth remineralisation [32]. Therefore it is important to highlight the importance of food textures, primarily 'stickiness', in parent education regarding prevention of dental decay in their children.

The ADG [16] and IFG [17] suggest that milk and dairy are excellent sources of calcium and should be consumed after 12 months of age. However, relatively few leaflets recommended milk and/or cheese as healthy snack options. Apart from general health benefits [33], both these dairy products have proven positive effects in reducing the negative impact of metabolic acids on teeth and restoring lost tooth enamel during the remineralisation process [34]. Although milk is a concern for early childhood caries due to pooling when fed through a bottle [6], it has health benefits [35] and anti-cariogenic effects when consumed appropriately. The dental benefits of cheese are less well-known and are due to several mechanisms. Herod [34] stated that chewing cheese leads to an increased stimulation of saliva which results in increased buffering of acids found in dental plaque and also delivers calcium and phosphate which enhances remineralisation [36].

The most prevalent bottle feeding message found in these leaflets advised not to leave an infant with a bottle of milk overnight, which is consistent with relevant message advocated in the ADG [16] and IFG [17]. Although 
some parents may find it difficult to put their child to sleep without the comfort of a bottle, it is healthier to allow a child to drink milk before bedtime and then follow this with toothbrushing. Only seven of the 43 leaflets discouraged filling bottles with other fluids such as fruit juice or cordial, rather than water. The lack of attention to this preventive health recommendation in paediatric dental health leaflets is a special cause for concern and requires remedying.

Breastfeeding was advocated in ten leaflets, none of which explicitly advised exclusive breastfeeding until 6 months of age as recommended by the ADG [16] and IFG [17]. A review by Ribeiro \& Ribeiro [37] found that breast milk had less potential to cause tooth decay than cow's milk and infant formula. Other studies have shown that breastfeeding transfers antibodies responsible for hindering bacterial growth, and the lactoferrin in breast milk has a bactericidal effect on cariogenic bacteria [38].

The practice of dipping a pacifier in sugary products to help put infants to sleep was discouraged in only some leaflets targeted at parents of infants. Bedtime feeding of sugary substances either in a bottle or as a coating on a pacifier not only has implications related to early childhood decay, but the increased caloric intake can impact negatively on general health by predisposing to obesity [39]. This message should be a core component of relevant leaflets.

Just over half $(n=24)$ of leaflets accurately identified fruit juice negatively with respect to dental caries. Fruit juices are generally acidic and contain free sugars - both of which have detrimental effects on teeth [7]. Conversely, fresh fruit is often considered a healthy food and is included as a healthy snack recommendation in the ADG [16]. It is important for parents to be educated on the differences between fruit juice and fresh fruit, particularly with regard to the free sugar and acid content in respect of dental health $[7,31,40]$.

In this study, more leaflets provided examples of recommended "good" foods and drinks, rather than providing examples of "bad" foods and drinks to avoid. The significance of the use of specific language in conveying health-related messages has been highlighted in the past [41]. More recently, it was reported in an Australian study that mothers of young children found the advice on bottle feeding confusing due to the use of language [42]. This is consistent with the idea that negative framing of messages, such as those encouraging people to eat a healthy diet, promotes avoidance behaviour while positive framing facilitates performance of prevention behaviours [43]. The effect of negative versus positive framing of prevention messages in dental health leaflets deserves research attention.

Pictures accompanied by simple phrases and captions have been shown to be beneficial in conveying health messages to patients as they improve comprehension and recall [44]. Research in experimental psychology and marketing highlights that humans have a cognitive preference for picture-based rather than text-based information: the so-called "picture-superiority effect" [45]. On the other hand, poorly captioned images and the use of ambiguous terms can detract from the intended message. There were some examples of ambiguous images and supporting text in the leaflets in this study. Leaflet 12 , for example, had an image recommending avoidance of "cool drinks", an Australian expression sometimes used to describe soft drinks or sugar-sweetened beverages, but provided no further clarification. As a result, parents may interpret this image and recommendation incorrectly and think that all cold drinks, including water and milk, are unhealthy. Additionally the message implies a false idea that any type of "warm drink" is acceptable, which may not be the case; it has been reported that acidic drinks at room temperature increase the risk for dental erosion. The need for clearer health education images and accompanying and concurrent messages is therefore warranted [46].

Although leaflets were sourced from most state and territory health departments and a variety of other organisations, the authors acknowledge that not all leaflets may have been located hence that the findings of this study may not be representative of all dental education leaflets in Australia.

\section{Conclusions}

There were some discordance between the informational content across paediatric dental health promotion leaflets and dietary and infant feeding guidelines in Australia. In addition, some dietary and infant feeding messages and imagery lacked clarity. Inconsistencies in similar pieces of information also occurred across leaflets; and few leaflets contained most or all of the pertinent dietary and infant feeding information messages to help prevent dental decay and erosion in children. Government Health Departments and other relevant agencies should ensure that advisory messages regarding diet and infant feeding, are clear, complete and consistent across all dental educational leaflets in Australia.

The core diet-related messages that should be included in ideal paediatric oral health leaflets are:

1. Infants should be exclusively breastfed until around 6 months of age followed by the introduction of solid foods; and breastfeeding should be continued until 12 months of age and beyond;

2. If infants are not breastfed, infant formulas should be used as an alternative to breast milk until 12 months of age; 
3. Infants should not go to bed with a bottle of milk, soft drink or fruit juice;

4. The frequent consumption of added sugars in foods and drinks, and in particular sticky foods with meals should be limited;

5. The consumption of acidic drinks, in particular fruit juices and carbonated beverages, should be limited;

6. Drink fluoridated tap water;

7. Introduce a sipper cup from age 6 months;

8. Pacifiers should not be dipped in honey, jam or any other sugary substance;

9. Do not share spoons or other eating utensils such as forks and chopsticks;

10.Eat two serves of fruit and five serves of vegetables daily.

\section{Abbreviations}

ADG: Australian dietary guidelines; IFG: Infant feeding guidelines; NHMRC: National health and medical research council; NSW: New South Wales; SA: South Australia; UNSW: University of New South Wales; WA: Western Australia; WHO: World Health Organisation

\section{Acknowledgements}

Not Applicable.

\section{Funding}

This study was supported by the Australian NHMRC Project Grant (1033213): Australian Dental Research Foundation, and NSW Health. Dr Amit Arora is supported by Australian NHMRC Early Career Fellowship (1069861) and Dr Jenny Doan was supported by the Australian Dental Research Foundation Student Grant.

\section{Availability of data and materials}

All the leaflets used in this study are publically available.

\section{Authors' contributions}

$A A, J S, D H$, and MFH conceptualised the study. AA, JD, JM and CP were involved in collection of the leaflets from different sources and data extraction. All authors were involved in the writing of the manuscript and approved the final version.

\section{Competing interests}

The authors declare that they have no competing interests.

\section{Consent for publication}

Not Applicable.

\section{Ethics approval and consent to participate}

This study did not require human research ethics approval as it did not involve study participants. Only analysis of publically available leaflets was undertaken.

\footnotetext{
Author details

'School of Science and Health, Western Sydney University, Campbelltown, NSW, Australia. ${ }^{2}$ Discipline of Paediatrics and Child Health, Sydney Medical School, Westmead, NSW, Australia. ${ }^{3}$ Oral Health Service, Sydney Local Health District and Sydney Dental Hospital, NSW Health, Surry Hills, NSW, Australia. ${ }^{4} \mathrm{COHORTE}$ Research Group, Ingham Institute of Applied Medical Research, Liverpool, NSW, Australia. ${ }^{5}$ Faculty of Dentistry, The University of Sydney, Westmead, NSW, Australia. ${ }^{6} \mathrm{Centre}$ for Primary Health Care and Equity, UNSW Australia, Randwick, NSW, Australia. ${ }^{7}$ School of Public Health, Curtin University, Perth, WA, Australia. ${ }^{8}$ Cancer Australia, Surry Hills, NSW, Australia.
}

Received: 13 September 2016 Accepted: 16 February 2017 Published online: 20 February 2017

\section{References}

1. Petersen PE, Bourgeois D, Ogawa H, Estupinan-Day S, Ndiaye C. The global burden of oral diseases and risks to oral health. Bull World Health Organ. 2005;83:661-9.

2. Moynihan P, Petersen PE. Diet, nutrition and the prevention of dental diseases. Public Health Nutr. 2004;7:201-26.

3. Bagramian RA, Garcia-Godoy F, Volpe AR. The global increase in dental caries - a pending public health crisis. Am J Dent. 2009;22:3-8.

4. Mejia G, Amarasena N, Ha D, Roberts-Thomson K, Ellershaw A. Child dental health survey Australia 2007: 30-year trends in child oral health. Canberra: Australian Institute of Health and Welfare; 2012. Contract No.: DEN 217.

5. Armfield JM, Spencer AJ. Quarter of a century of change: caries experience in Australian children, 1977-2002. Aust Dent J. 2008:53:151-9.

6. Arora A, Schwarz E, Blinkhorn AS. Risk factors for early childhood caries in disadvantaged populations. J Investig Clin Dent. 2011;2:223-8.

7. World Health Organization. Guideline: sugars intake for adults and children. Geneva: Wold Health Organization; 2015. Accessed 1 Sept 2016 http://www. who.int/nutrition/publications/guidelines/sugars_intake/en/.

8. Petersen PE. The World Oral Health report 2003: continuous improvement of oral health in the 21st century - the approach of the WHO global oral health programme. Community Dent Oral Epidemiol. 2003;31:3-23.

9. Sheiham A, Watt RG. The common risk factor approach: a rational basis for promoting oral health. Community Dent Oral Epidemiol. 2000;28:399-406.

10. Hooley M, Skouteris H, Millar L. The relationship between childhood weight, dental caries and eating practices in children aged 4-8 years in Australia, 2004-2008. Pediatr Obes. 2012;7:461-70.

11. Hayden C, Bowler JO, Chambers S, Freeman R, Humphris G, Richards D, et al. Obesity and dental caries in children: a systematic review and metaanalysis. Community Dent Oral Epidemiol. 2013;41:289-308.

12. Sheiham A. Major changes in strategies are needed to promote oral health worldwide. J Public Health Dent. 2013;73:87-8.

13. Australian Bureau of Statistics. 4364.0.55.011 - Australian health survey: consumption of added sugars, 2011-2012. Canberra: Australian Bureau of Statistics; 2016. Accessed 1 Sept 2016 http://www.abs.gov.au/ausstats/abs@. $\mathrm{nsf} / \mathrm{mf} / 4364.0 .55 .011$.

14. Tinanoff N, Palmer CA. Dietary determinants of dental caries and dietary recommendations for preschool children. J Public Health Dent. 2000;60:197-206.

15. Moynihan P. Foods and factors that protect against dental caries. Nutr Bull. 2000;25:281-6.

16. National Health and Medical Research Council. Australian dietary guidelines. Canberra: National Health and Medical Research Council; 2013.

17. National Health and Medical Research Council. Infant feeding guidelines. Canberra: National Health and Medical Research Council; 2012.

18. McMullan M. Patients using the internet to obtain health information: how this affects the patient-health professional relationship. Patient Educ Couns. 2006;63:24-8.

19. Sillence E, Briggs P, Harris PR, Fishwick L. How do patients evaluate and make use of online health information? Soc Sci Med. 2007;64:1853-62.

20. Arora A, Lam AS, Karami Z, Do LG, Harris MF. How readable are Australian paediatric oral health education materials? BMC Oral Health. 2014;14:111.

21. Watt RG, McGlone P, Kay EJ. Prevention. Part 2: dietary advice in the dental surgery. Br Dent J. 2003;195:27-31.

22. Moynihan PJ. Dietary advice in dental practice. Br Dent J. 2002;193:563-8.

23. George D, Mallery P. SPSS for windows step by step: a simple guide and reference. 4th ed. Boston: Allyn \& Bacon; 2003.

24. Gustafsson BE, Quensel CE, Lanke LS, Lundqvist C, Grahnen H, Bonow BE, et al. The Vipeholm dental caries study; the effect of different levels of carbohydrate intake on caries activity in 436 individuals observed for five years. Acta Odontol Scand. 1954;11:232-64.

25. Rugg-Gunn A. Dental caries: strategies to control this preventable disease. Acta Med Acad. 2013;42:117-30.

26. Lussi A. Erosive tooth wear - a multifactorial condition of growing concern and increasing knowledge. Monogr Oral Sci. 2006;20:1-8.

27. Armfield JM. Community effectiveness of public water fluoridation in reducing Children's dental disease. Public Health Rep. 2010;125:655-64.

28. Armfield JM, Spencer AJ. Consumption of nonpublic water: Implications for children's caries experience. Community Dent Oral Epidemiol. 2004;32:283-96. 
29. National Health and Medical Research Council. NHMRC public statement: efficacy and safety of fluoridation. Canberra: National Health and Medical Research Council; 2007.

30. Daniels MC, Popkin BM. Impact of water intake on energy intake and weight status: a systematic review. Nutr Rev. 2010;68:505-21.

31. Arora A, Evans RW. Is the consumption of fruit cariogenic? J Investig Clin Dent. 2012;3:17-22.

32. Touger-Decker R, van Loveren C. Sugars and dental caries. Am J Clin Nutr. 2003;78:881S-92S.

33. Prentice RL, Pettinger MB, Jackson RD, Wactawski-Wende J, Lacroix AZ, Anderson $\mathrm{GL}$, et al. Health risks and benefits from calcium and vitamin $\mathrm{D}$ supplementation: Women's health initiative clinical trial and cohort study. Osteoporos Int. 2013;24:567-80.

34. Herod EL. The effect of cheese on dental caries: a review of the literature. Aust Dent J. 1991;36:120-5.

35. Bonjour JP, Carrie AL, Ferrari S, Clavien H, Slosman D, Theintz G, et al. Calciumenriched foods and bone mass growth in prepubertal girls: a randomized, double-blind, placebo-controlled trial. J Clin Invest. 1997;99:1287-94.

36. Kshket S, DePaola DP. Cheese consumption and the development and progression of dental caries. Nutr Rev. 2002;60:97-103.

37. Ribeiro NM, Ribeiro MA. Breastfeeding and early childhood caries: a critical review. J Pediatr. 2004:80:S199-210.

38. Arnold RR, Cole MF, McGhee JR. A bactericidal effect for human lactoferrin Science. 1977;197:263-5.

39. Gooze RA, Anderson SE, Whitaker RC. Prolonged bottle use and obesity at 5 . 5 years of age in US children. J Pediatr. 2011;159:431-6.

40. Miller C. Enamel erosive properties of fruit and fruit juices. J Nutr. 1950;41:63-71.

41. Snyder LB. Health communication campaigns and their impact on behavior. J Nutr Educ Behav. 2007;39:S32-40.

42. Arora A, McNab MA, Lewis MW, Hilton G, Blinkhorn AS, et al. 'I can't relate it to teeth': a qualitative approach to evaluate oral health education materials for preschool children in New South Wales, Australia. Int J Paediatr Dent. 2012:22:302-9.

43. Rothman AJ, Salovey P, Antone C, Keough K, Martin CD. The influence of message framing on intentions to perform health behaviors. J Exp Soc Psychol. 1993;29:408-33.

44. Houts PS, Doak CC, Doak LG, Loscalzo MJ. The role of pictures in improving health communication: a review of research on attention, comprehension, recall, and adherence. Patient Educ Couns. 2006;61:173-90.

45. Sansgiry SS, Cady PS, Adamcik BA. Consumer comprehension of information on over-the-counter medication labels: effects of picture superiority and individual differences based on age. J Pharm Mark Manage. 1997;11:63-76.

46. Dugmore CR, Rock WP. A multifactorial analysis of factors associated with dental erosion. Br Dent J. 2004:196:283-6.

\section{Submit your next manuscript to BioMed Central and we will help you at every step:}

- We accept pre-submission inquiries

- Our selector tool helps you to find the most relevant journal

- We provide round the clock customer support

- Convenient online submission

- Thorough peer review

- Inclusion in PubMed and all major indexing services

- Maximum visibility for your research

Submit your manuscript at www.biomedcentral.com/submit
Biomed Central 